\title{
Abdominal aortitis associated with Crohn disease
}

\author{
Vinaya Gaduputi MD, Hassan Tariq MD, Kaylan Kanneganti MD
}

\section{CASE PRESENTATION}

A 26-year-old woman who was diagnosed with Crohn disease when she was 12 years of age presented with a two-week history of nausea, vomiting, worsening diarrhea and bilateral lower abdominal pain. The patient had a protracted history of Crohn disease treated with mesalamine, tapering short courses of corticosteroids for exacerbations and then 6-mercaptopurine therapy initiated three years before this presentation. Nine months before the patient presented, she was also started on subcutaneous adalimumab and maintained on a dose of $40 \mathrm{mg}$ every other week. Her white blood cell count was $10 \times 10^{9} / \mathrm{L}(65.5 \%$ segmented neutrophils, $28.9 \%$ lymphocytes, $4.8 \%$ monocytes), with a hemoglobin level of $123 \mathrm{~g} / \mathrm{L}$ and a platelet count of $164 \times 10^{9} / \mathrm{L}$. An abdominal computed tomography scan revealed multifocal areas of mural thickening with narrowing in the colon (Figure 1), long-segment minimal thickening with narrowing of the upper abdominal aorta and maximal luminal narrowing in an infrarenal aortic segment (Figure 2). These findings were suggestive of aortitis, which is very rarely associated with Crohn disease.

\section{DISCUSSION}

Aortitis associated with Crohn disease can be extensive, involving the entirety of the aorta. However, the usual sites of involvement include the aortic valve leaflets leading to aortic insufficiency (1) and the aortic root in the form of aneurysmal dilation. Aneurysmal dilation and occlusion of the aortic arch and aortic branches have also been reported. Localized disease involving only a short segment of aorta, such as in our patient, could lead to the development of aortic mural thrombus and subsequent embolization (2). It is of paramount importance to rule out Takayasu arteritis, which is known to be associated with Crohn disease (3). It is noteworthy that involvement of the aorta in Crohn disease frequently occurs in association with ankylosing spondylitis and a positive human leukocyte antigen-B27 phenotype (4). The patient demonstrated sacroiliitis on computed tomography scan of the abdomen (Figure 3), which could be related to an underlying spondylarthropathy versus the Crohn disease itself.

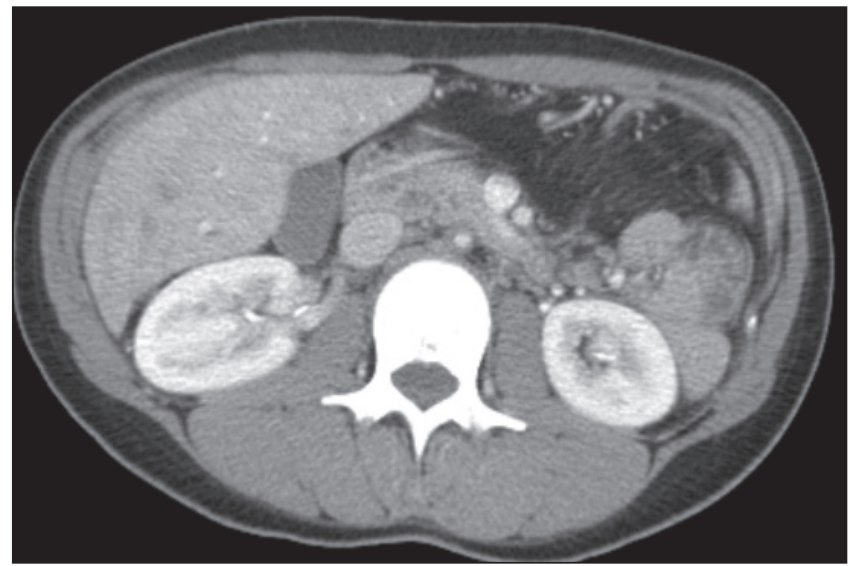

Figure 1) Transverse section showing decreased calibre of the abdominal aorta

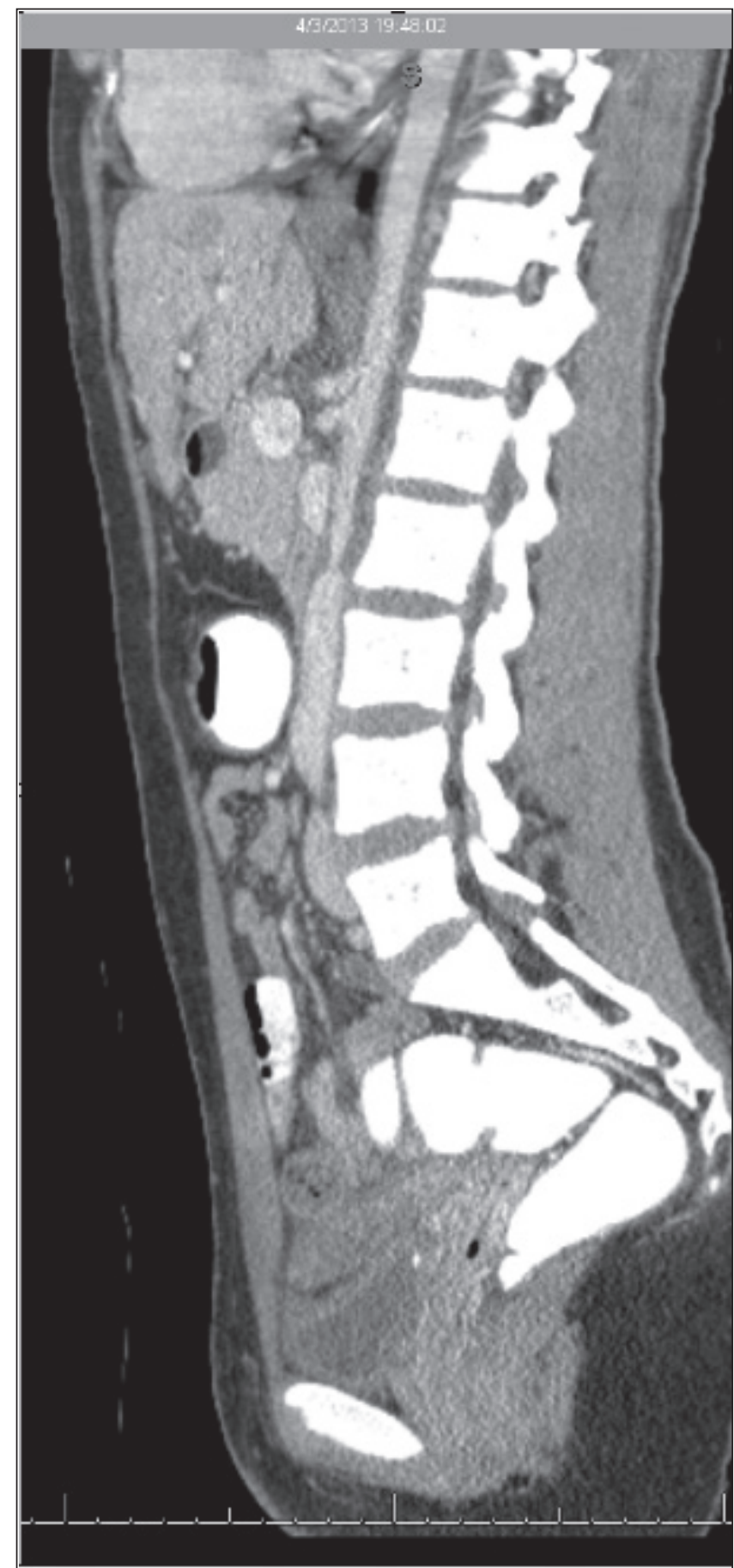

Figure 2) Sagittal section showing maximal luminal narrowing in an infrarenal aortic segment

Bronx Lebanon Hospital Center, Bronx, New York, USA

Correspondence: Dr Hassan Tariq, Bronx Lebanon Hospital Center, 1650 Selwyn Avenue, Suite 10C, Bronx, New York 10457, USA.

Telephone 718-900-1234,e-mail htariq@bronxleb.org

Received for publication July 31, 2013. Accepted September 19, 2013 


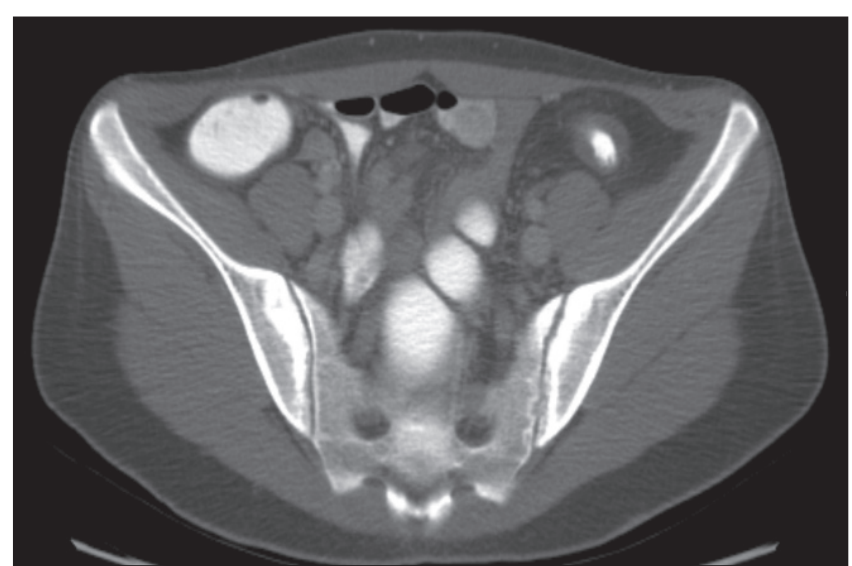

Figure 3) Transverse section showing bilateral sacroiliitis

\section{REFERENCES}

1. Ozsöyler I. Cardiovascular involvement in Crohn's disease in the absence of ankylosing spondylitis. Heart Vessel 2005;20:164-6.

2. Novacek G. Aortic mural thrombi in patients with inflammatory bowel disease: Report of two cases and review of the literature. Inflamm Bowel Dis 2004;10:430-5.

3. Biagi P. Takayasu's arteritis and Crohn's disease: An unusual association. Report on two cases. Dig Liver Dis 2001;33:487-91.

4. Wäckerlin A. [Aortic valve insufficiency in Crohn disease]. Schweizerische medizinische Wochenschrift 1997;127:935-9. 


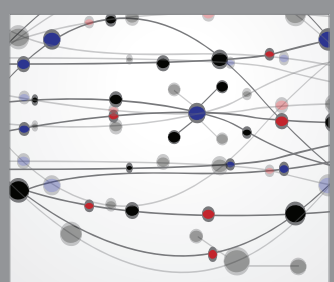

The Scientific World Journal
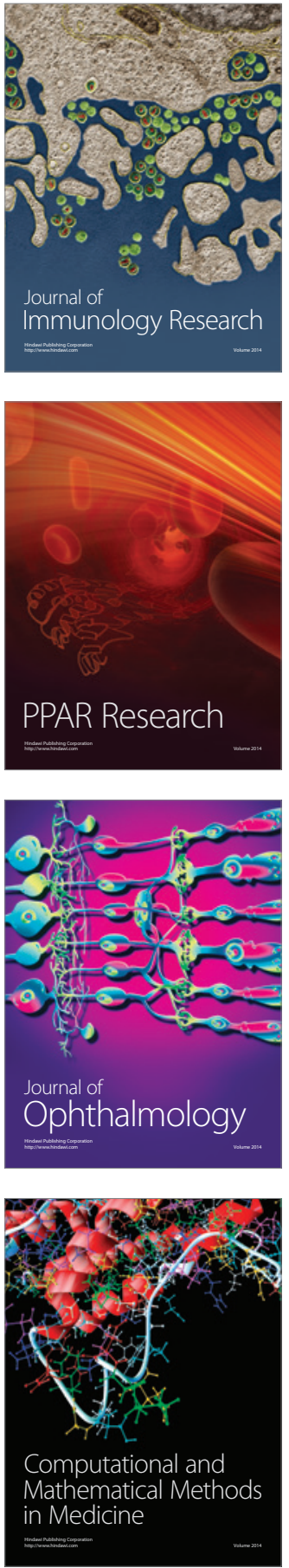

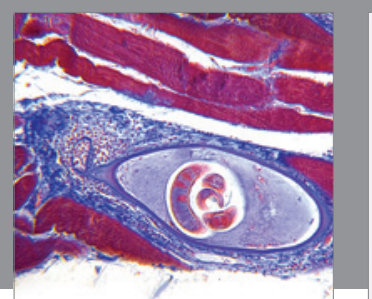

Gastroenterology Research and Practice

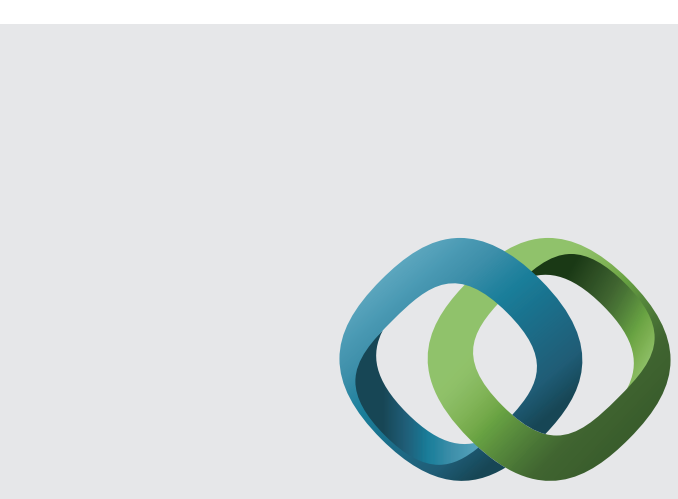

\section{Hindawi}

Submit your manuscripts at

http://www.hindawi.com
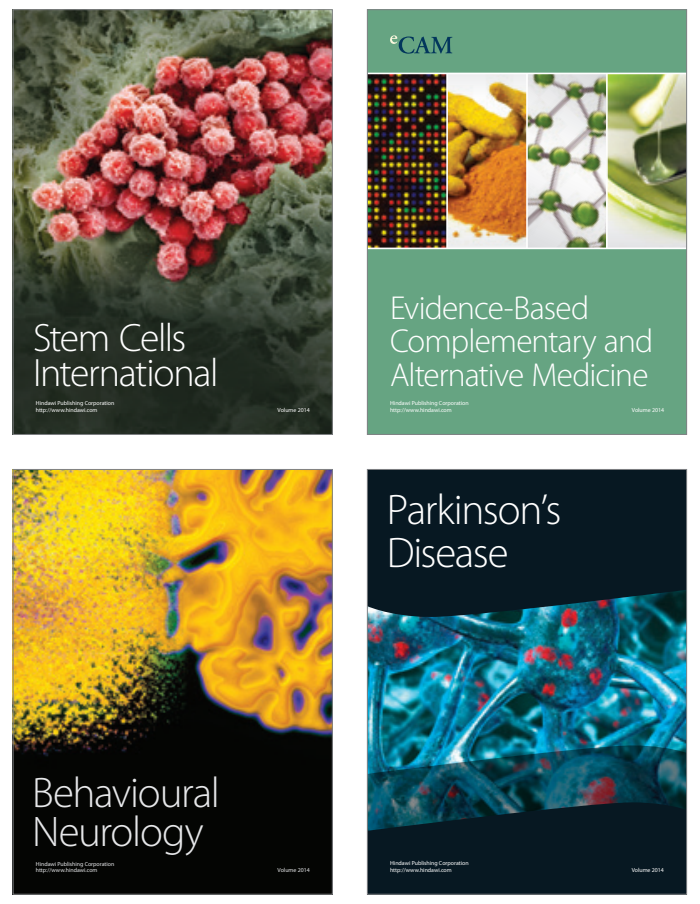
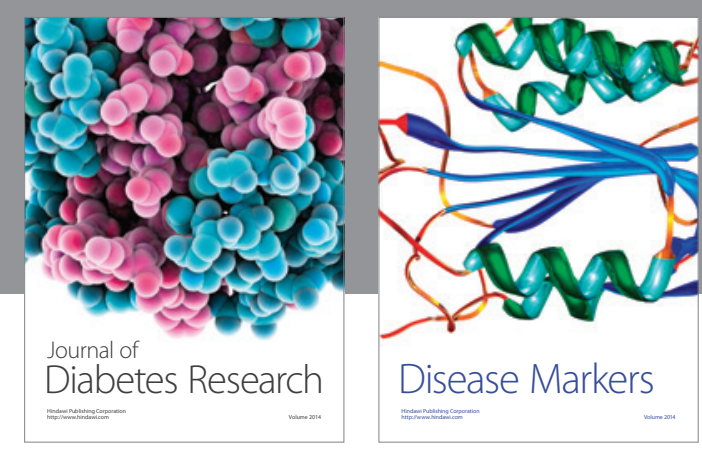

Disease Markers
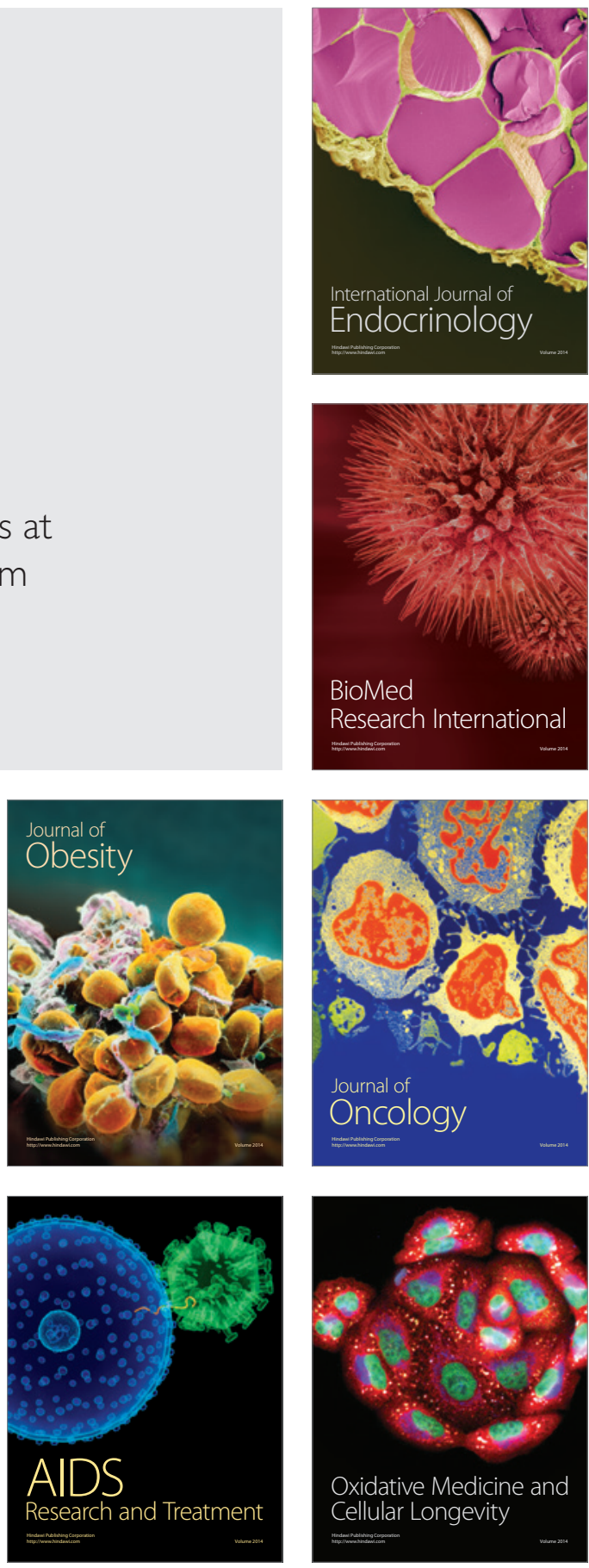